STOMACH

\title{
High incidence of adenocarcinoma arising from the right side of the gastric cardia in NW Iran
}

\author{
M H Derakhshan, A Yazdanbod, A R Sadjadi, B Shokoohi, K E L McColl, R Malekzadeh
}

Gut 2004;53:1262-1266. doi: 10.1136/gut.2003.035857

See end of article for authors' affiliations .....................

Correspondence to: Professor R Malekzadeh, Digestive Disease Research Centre, Tehran University of Medical Sciences, Shariati Hospital, North Kargar Ave, 14114 Tehran, Iran; malek@ams.ac.ir

Revised version received 19 February 2004 Accepted for publication 19 March 2004
Background: In the West, the subsite incidence of gastric cancer has changed in recent decades, with cancer of the cardia increasing in incidence and that of the more distal stomach decreasing. NW Iran has a very high incidence of upper gastrointestinal cancer and we have examined the anatomical site specific incidence in this geographical region.

Method and materials: Of 33718 patients who visited our clinic from March 2000 to Jan 2003, 3119 (9.3\%) with persistent upper gastrointestinal symptoms underwent upper gastrointestinal fibreoptic endoscopy. Exact tumour site, subsite, and axial view were determined. Demographic data including age, sex, and place of residence were assessed. Using matched data from the cancer registry and endoscopic survey, age standardised rates (ASR) for all subsites were calculated.

Results: Upper gastrointestinal cancer was diagnosed histologically in 499 patients (16.0\%). The most frequent site was the gastric cardia (126 (25.3\%)) followed by the oesophageal body $(90(18.0 \%))$, antrum $(82(16.4 \%))$, corpus $(74(14.8 \%))$, distal oesophagus (57 (11.4\%)), gastro-oesophageal junction (47 $(9.4 \%))$, and proximal oesophagus $(22(4.4 \%))$. From axial views of the cardia, $51.4 \%$ and $6.8 \%$ of tumours were found to originate from the lesser and greater curve, respectively. ASR for gastric cancer were 51.2 in males and 15.4 in females. Cardia cancer with ASR of 26.4 in males and 8.6 in females was the major component of gastric cancer.

Conclusion: NW Iran is a geographical region with a very high incidence of cardia cancer and with the great majority originating from the right side of the cardia. This suggests a locally acting luminal carcinogen. Studying the aetiology of this cancer in NW Iran is likely to increase our understanding of the rising incidence of this cancer throughout the Western world.
G astric cancer remains the world's third most common malignancy. ${ }^{1}$ However, in the West, there have been marked changes in the incidence of cancer at different anatomical subsites of the stomach. Adenocarcinoma of the most proximal cardia region of the stomach and adjacent gastro-oesophageal junction has increased in incidence over the past 25 years and at a rate which exceeds that of any other cancer. ${ }^{2-4}$ In contrast, adenocarcinoma of the more distal stomach (non-cardia cancer) has been progressively falling in incidence for at least the last 50 years. ${ }^{5}$ In Japan, the incidence of gastric cancer is particularly high, and 90\% are located distal to the cardia. ${ }^{6}$

These opposing incidence trends indicate distinct aetiologies for these cancer of the two subsites of the stomach. Consistent with this, cancers at these subsites also differ with respect to the underlying gastric phenotype against which the cancer develops. Non-cardia gastric cancer occurs in patients with Helicobacter pylori induced atrophic gastritis and accompanying hypochlorhydria. ${ }^{7}$ In contrast, cancer of the cardia and gastro-oesophageal junction occurs in subjects with normal acid secreting stomachs and is not associated with $H$ pylori infection. ${ }^{7} 9^{10}$

The fall in incidence of non-cardia gastric cancer in the western world may be explained by the decrease in incidence of $H$ pylori infection and associated atrophic gastritis and hypochlorhydria. However, the cause of the rising incidence of cancer of the cardia region of the stomach and gastrooesophageal junction is unknown. Gastro-oesophageal reflux may be involved in the aetiology of adenocarcinoma within the oesophagus as there is an association between the two conditions. ${ }^{11}$ However, there is little association between cardia cancer and reflux disease, and its aetiology remains unclear. ${ }^{11}$
Gastric cancer is the most common malignancy in Iran and its incidence is particularly high in the Ardabil province in the north west of the country. ${ }^{12-16}$ In this province, the age standard incidence rate is 49.1 and 25.4 per 100000 persons per year in males and females, respectively. The cause of the high incidence of gastric cancer in this geographical region is unknown. In view of the recent recognition that the different anatomical subsites of gastric cancer have different aetiologies, we have performed a detailed analysis of the distribution and subsite incidence of upper gastrointestinal cancer in this geographical region.

\section{METHOD AND MATERIALS}

\section{Endoscopic survey}

This prospective study was conducted in the first established subspecialty outpatient gastrointestinal clinic in Ardabil City. Of the 33718 patients who attended this clinic with a chief complain of upper gastrointestinal symptoms over a 33 month period (March 2000-January 2003), 3119 patients $(9.3 \%)$ who were older than 45 year age or were found to have at least one alarming gastrointestinal sign or symptom (dysphagia, persistent abdominal pain, weight loss, anaemia, abdominal mass, persistent vomiting) were enrolled. Using $10 \%$ lidocaine spray in the pharynx, standard upper gastrointestinal endoscopy was performed. According to WHO/ IARC guidelines for classification of adenocarcinoma of the gastro-oesophageal junction area, the following definitions were used for exact localisation of tumours ${ }^{17}$ :

Abbreviations: ASR, age standardised rate 
Table 1 Topography and histology of upper gastrointestinal tumours

\begin{tabular}{lccllc}
\hline & \multicolumn{3}{l}{ Histological type } & & \\
\cline { 2 - 6 } Site & Adenocarcinoma & $\begin{array}{l}\text { Squamous cell } \\
\text { carcinoma }\end{array}$ & $\begin{array}{l}\text { Malignant } \\
\text { lymphoma }\end{array}$ & $\begin{array}{l}\text { Carcinoid } \\
\text { tumour }\end{array}$ & Total (n (\%)) \\
\hline Proximal oesophagus & 1 & 21 & & & $22(4.4)$ \\
Middlle oesophagus & 5 & 85 & & & $90(18.0)$ \\
Distal oesophagus & 20 & 37 & & & $57(11.4)$ \\
GOJ & 42 & 5 & & 1 & $47(9.4)$ \\
Gastric cardia & 125 & & 1 & $126(25.3)$ \\
Gastric corpus & 73 & & 2 & 1 & $74(14.8)$ \\
Gastric antrum & 79 & & 1 & 2 & $1(16.4)$ \\
Gastrojejunostomy & 345 & 148 & 4 & 2 & $499(100.0)$ \\
Total & 345 & & & & \\
\hline GOJ, gastro-oesophageal junction. & &
\end{tabular}

- Adenocarcinoma of gastro-oesophageal junction: when a tumour crosses the gastro-oesophageal junction regardless of the site of the tumour bulk.

- Adenocarcinoma of oesophagus: when the tumour is entirely above the gastro-oesophageal junction.

- Adenocarcinoma of gastric cardia: when the tumour is entirely below the gastro-oesophageal junction, centred within $2 \mathrm{~cm}$ distal to the junction.

According to observed and portrayed lesions on endoscopy sheets, we considered the cardia at endoscopy as two right and left semicircles. The right semicircle was located just at the continuity or direction of the lesser curvature. The left semicircle was located just at the continuity of the fundal area and greater curvature. By definition, tumours which were more than $80 \%$ within the right semicircle were named right sided lesions. For the left side, the same definition was used. The oesophagus was carefully scrutinised for location of the gastro-oesophageal junction and Z-line. Location of tumours was registered accurately and at least six punch biopsies were obtained from all tumours. Biopsy specimens were oriented, fixed in $10 \%$ buffered formalin, sectioned, and stained using the haematoxylin-eosin technique. Experienced pathologists then examined the specimens for evidence of cancer.

Studies were undertaken to validate the endoscopic localisation of the junction tumours. This was performed in patients who underwent surgery by comparing surgical and gross pathological descriptions of the site of the tumour with those recorded at endoscopy.

\section{Comparing estimated incidence rates}

Data from the Ardabil Cancer Registry (ACR) did not have sufficient information on subsite distribution of upper gastrointestinal tumours; only cases registered at Yazdanbod Clinic had endoscopic localisation of tumours. Therefore, we used these patients as incident cases. For definition of the population at risk, all residents of areas covered by this clinic were included in the census. This population was approximately $48 \%$ of the entire province population and was 560608 persons at the midpoint of the study interval. To best compare our data with those of the Scottish Cancer Registry, oesophageal tumours were divided into two histological categories (squamous cell carcinoma and adenocarcinoma), and all adenocarcinomas of the stomach were classified as cardia or non-cardia cancer. Results are minimal rates and approximate estimates from clinic based data, and cannot be attributed exactly to population based registry systems. All estimates are presented as age standardised rates (ASR); the reference population for standardisation was the World Standard Population. ${ }^{18}$ Age groups in the reference population are presented in five year categories but we categorised our age groups intol0 year intervals. We used a direct method for standardisation. ${ }^{19}$

\section{RESULTS}

During the period of study, 523 cases of suspected upper gastrointestinal tract cancer were found endoscopically and a diagnosis of cancer was confirmed by histopathology of the endoscopic biopsies in 493 of these cases. Pathological confirmation was also available for an additional six surgically resected tumours, thus making a total of 499 upper gastrointestinal cancers. Mean age of all patients was 63.2 (10.6) years and the male to female ratio was 2.2:1.

\section{Subsite distribution}

Of these 499 gastro-oesophageal cancer cases, 169 (33.9\%) were in the oesophagus, $282(56.5 \%)$ in the stomach, 47 $(9.4 \%)$ at the gastro-oesophageal junction, and one $(0.2 \%)$ at a gastrojejunostomy stoma. Of the oesophageal cancers, 22 $(13.0 \%), 90(53.3 \%)$, and $57(33.7 \%)$ were at the upper, middle, and lower thirds of the oesophagus, respectively. Of the stomach cancers, $126(43.7 \%)$ were located in the cardia region. The antrum and body region of the stomach were the second and third most common sites, with $82(29.1 \%)$ and 74 $(26.2 \%)$ cases, respectively (table 1$)$.

Overall, $46 \%(230 / 499)$ of all tumours and 54\% (187/345) of adenocarcinomas of the upper gastrointestinal tract originated from near the gastro-oesophageal junction involving the lower oesophagus, gastro-oesophageal junction, or gastric cardia. As shown in (table 2), 41.7\% of cardia cancers

Table 2 Endoscopic localisation of malignant tumours of the junctional area

\begin{tabular}{|c|c|c|c|c|}
\hline Tumour location & $\begin{array}{l}\text { Right } \\
\text { (n (\%)) }\end{array}$ & $\begin{array}{l}\text { Circular } \\
\text { (n (\%)) }\end{array}$ & $\begin{array}{l}\text { Left } \\
\text { (n (\%)) }\end{array}$ & $\begin{array}{l}\text { p Value } \\
\text { (rt } v \text { lt) }\end{array}$ \\
\hline Distal oesophagus & $5(20.8)$ & $17(70.8)$ & $2(8.3)$ & NS \\
\hline GOJ & $12(29.3)$ & $26(63.4)$ & $3(7.3)$ & NS \\
\hline Cardia & $53(51.4)$ & $43(41.7)$ & $7(6.8)$ & $<0.05$ \\
\hline Total & $70(41.7)$ & $86(51.2)$ & $12(7.1)$ & $<0.05$ \\
\hline
\end{tabular}


Table 3 Surgical localisation of malignant tumours of the junctional area

\begin{tabular}{lllll}
\hline Tumour location & $\begin{array}{l}\text { Right } \\
\text { (n (\%)) }\end{array}$ & $\begin{array}{l}\text { Circular } \\
\text { (n }(\%))\end{array}$ & $\begin{array}{l}\text { Left } \\
\text { (n (\%)) }\end{array}$ & Total \\
\hline Distal oesophagus & 1 & 8 & 0 & 9 \\
GOJ & 11 & 15 & 5 & 31 \\
Cardia & 40 & 13 & 6 & 59 \\
Total & $52(53 \%)$ & $36(36 \%)$ & $11(11 \%)$ & $99(100 \%)$ \\
\hline \multicolumn{5}{l}{ GOJ, gastro-oesophageal junction. } \\
\end{tabular}

were circumferential, $51.4 \%$ located at the right side, and $6.8 \%$ at the left side. Therefore, $88 \%(53 / 60)$ of early cardia cancers were seen to originate from the right side. Circumferential tumours were more frequent at the gastrooesophageal junction and distal oesophagus, being $63.4 \%$ and $70.8 \%$, respectively.

Only 99 of 178 patients with cancers arising near to the gastro-oesophageal junction underwent surgical intervention and had a reliable surgical and pathological topographic report. Of the 59 cardia cancers, $40(68 \%)$ were on the right side, six $(10 \%)$ on the left side, and $13(22 \%)$ circumferential (table 3 ). The propensity for the cardia cancers to arise from the right side was thus confirmed.

\section{Histopathology}

A total of $345(69.1 \%)$ upper gastrointestinal tumours were adenocarcinomas, 148 (29.7\%) squamous cell carcinomas, four $(0.8 \%)$ malignant lymphomas, and two $(0.4 \%)$ carcinoid tumours. Except for one case of carcinoid tumour, almost all (99.2\%) cancers of the cardia were adenocarcinomas. Based on the Lauren classification of adenocarcinomas, $48.0 \%$ of the cardia cancers were of the intestinal-type, $35.2 \%$ diffuse-type $(\mathrm{p}<0.05)$, and $16.8 \%$ undeterminable (table 4$)$. At the distal oesophagus, $20(35.1 \%)$ tumours were adenocarcinomas and $37(64.9 \%)$ were squamous cell carcinomas. At the gastrooesophageal junction, only five (10.6\%) tumours were squamous cell carcinomas and the remaining $89.4 \%$ were adenocarcinomas. Mean age of all patients with adenocarcinoma were significantly higher than those with squamous cell carcinoma $(64.3(10.4) v 60.9(10.8) ; \mathrm{p}<0.05)$. Also, mean age of patients with intestinal-type adenocarcinomas $(65.8$ (8.7)), was higher than patients with diffuse-type adenocarcinoma $(62.1(10.8))(\mathrm{p}<0.05)$.

\section{Estimated incidence rates}

Crude incidence rates for all upper gastrointestinal tumours were 43.7 per 100000 per year in males and 20.1 per 100000 per year in females. ASR of all upper gastrointestinal tumours in males and females were 69.1/100 000/year and 36.4/ 100 000/year, respectively.

ASR of gastric cancer were 51.2 in males and 15.4 in females. Cardia cancer, with ASR of 26.4 in males and 8.6 in females, was the major component of gastric cancer. Cancer of the cardia was the most common upper gastrointestinal malignancy in males but in females oesophageal squamous cell carcinoma with an ASR of 17.8 was more common. Irrespective of sex differences, adenocarcinoma of the cardia and oesophageal squamous cell carcinoma were the first and second incident upper gastrointestinal malignancies in Ardabil.

\section{Age}

The youngest patient was a 22 year male with diffuse-type adenocarcinoma of the gastric corpus and the oldest was a 90 year old male with intestinal-type adenocarcinoma of the cardia. Patients with upper oesophageal tumour had the lowest mean age $(58.9(10.7))$ and patients with gastric corpus tumour had the highest mean age (66.4 (9.8) years). Mean age of cardia cancer patients was 64.2 (9.1) years. With the exception of mean age in antral cancer patients, we observed an increasing trend in age from proximal to distal tumour sites. Patients with right sided gastric cardia cancer had a lower age than those with left sided cancer $(65.2(9.1) v$ 69.3 (5.8); $<<0.05$ ).

\section{Place of residence Living place}

A total of $344(70.2 \%)$ and $146(29.8 \%)$ patients lived in rural and urban areas, respectively. Place of residence had no effect on the frequency of cardia cancer but comparing gastric cancer as a whole versus oesophageal cancer, urban dwellers had a greater risk of having gastric cancer than rural dweller (odds ratio 1.77 (95\% confidence interval 1.2-2.7)).

\section{DISCUSSION}

This study indicates that a high proportion of gastrooesophageal cancers diagnosed in this geographical region occur at the cardia region of the stomach; $24.6 \%$ of all cancers and $36.2 \%$ of adenocarcinomas occurring throughout the oesophagus or stomach occurred at this anatomical site. More cancers occurred at the cardia than at any other anatomical subsite. This is consistent with earlier observations. ${ }^{16}$

The high proportion of cancers occurring at the cardia could be due to a high incidence of cancer at this site or, alternatively, a low incidence of cancer in other regions of the upper gastrointestinal tract. We therefore assessed the incidence of cancer to allow comparison with values reported from other world regions. The ASR of gastric cancer, irrespective of anatomical subsite, in the Ardabil region was

Table 4 Type of adenocarcinoma according to the Lauren classification

\begin{tabular}{lccll} 
& \multicolumn{2}{l}{ Type of adenocarcinoma } & \\
\cline { 2 - 3 } Site & Intestinal $(\mathbf{n}(\%))$ & Diffuse $(\mathbf{n}(\%))$ & p Value \\
\hline Distal oesophagus & $2(50.0)$ & $2(50.0)$ & NS \\
GOJ & $21(70.0)$ & $9(30.0)$ & $<0.05$ \\
Gastric cardia & $60(57.7)$ & $44(42.3)$ & NS \\
Gastric corpus & $30(49.2)$ & $31(50.8)$ & NS \\
Gastric antrum & $28(59.6)$ & $19(40.4)$ & NS \\
Total & $141(57.3)$ & $105(42.7)$ & $<0.05$ \\
\hline
\end{tabular}

GOJ, gastro-oesophageal junction.

Percentages show only determinable cases. 
Table 5 Upper gastrointestinal cancer incidence from the Scottish Cancer Registry 1999 compared with the results of our study

\begin{tabular}{lllll}
\hline & $\begin{array}{l}\text { Oesophagus squamous } \\
\text { cell carcinoma }\end{array}$ & $\begin{array}{l}\text { Oesophagus } \\
\text { adenocarcinoma }\end{array}$ & $\begin{array}{l}\text { Stomach } \\
\text { cardia }\end{array}$ & $\begin{array}{l}\text { Stomach non- } \\
\text { cardia }\end{array}$ \\
\hline Ardabil ASR, male & 15.1 & 2.8 & 26.4 & 24.8 \\
Scotland ASR, male & 3.8 & 6.0 & 3.9 & 8.7 \\
Ardabil ASR, female & 17.8 & 3.2 & 8.6 & 6.8 \\
Scotland ASR, female & 3.2 & 1.4 & 1.6 & 4.6 \\
\hline ASR, age standardised rate. & & & \\
\hline
\end{tabular}

51.2 in males and 15.4 in females. This incidence rate is high compared with other countries and within the top quintile of reported incidences. ${ }^{20}$ Less data are available on the actual incidence of cancer of the gastric cardia in different countries. However, the incidence in the Ardabil region is substantially higher than available reports from 10 European countries, ${ }^{21-23}$ the USA, ${ }^{2}$ Japan, ${ }^{6}$ and Korea. ${ }^{24}$ Detailed subsite incidence rates are available for Scotland, which also has a high incidence of upper gastrointestinal cancer. ${ }^{25}$ However, cardia cancer ASR in NW Iran is more than six times that of Scotland (table 5). We therefore conclude that the large proportion of cancers occurring at the cardia region of the stomach in this geographical area reflects a particularly high incidence of cancer at this anatomical location.

In view of the recent recognition of the importance of cancer subsite to aetiology, we examined the location of the cardia cancer in more detail. This indicated that there was a clear propensity for cardia cancers to arise from the right side (that is, lesser curve) rather than from the left side (or greater curvature). As far as we are aware, this is the first study to document the radial distribution of cardia cancer.

Another geographical region with a very high incidence of cardia cancer is the Linxian region of China. ${ }^{26}$ Professor GuoQing Wang of the Chinese Academy of Medical Sciences has vast experience in endoscopic diagnosis and surgical resection of cardia cancer in China. In a personal communication, he informed us that more than $85 \%$ of early cancers of the cardia are found on the right side.

The cardia represents a relatively small region of the stomach with a surface area of only $5-10 \%$ of the entire stomach. The small area of the cardia means that its cancer incidence expressed as per unit of epithelial surface area is extremely high. This high local incidence increases further when one considers that most are occurring on the right side of the cardia.

What is the explanation for the high incidence of cancers originating at the right side of the gastric cardia? This is an important question as it should provide insight into the aetiology of the cancer. Previous studies have indicated lack of a positive association between $H$ pylori infection and cancer of the gastric cardia. ${ }^{27}$ However, it is possible that there are geographical differences in the association between $H$ pylori and cardia cancer as some Western countries found a negative association $^{28}$ and a Chinese study a positive association. ${ }^{26}$ Studies have shown little association between reflux disease and cancer at this anatomical site. ${ }^{11}$ The Ardabil region has a high incidence of $H$ pylori infection $(>80 \%)$ and a substantial incidence of reflux disease. ${ }^{29}$ In addition, 30\% smoke, less than 5\% drink alcohol, and $60 \%$ have a body mass index greater than $25 .{ }^{29}$ However, none of these can adequately account for the high incidence of cardia cancer.

It is generally recognised that epithelial cancers are a result of luminal factors. Therefore, luminal factors acting maximally at the cardia and particularly at its right side have to be considered. The gastric cardia is where ingested material and swallowed saliva first enters the stomach. It has also been shown that on entering the stomach, non-solid material proceeds down the lesser curve (that is, right side) following the "Magenstrasse" or "canalis gastricus" formed by the longitudinal mucosal folds. ${ }^{30}$ The right side of the cardia will therefore have particularly high exposure to carcinogens or precarcinogens in swallowed liquid or saliva. Interestingly, the lesser curve has previously been recognised as the region of the stomach with the highest incidence of incomplete metaplasia. $^{31}$

The Ardabil region is characterised by a high incidence of cancer throughout the upper gastrointestinal tract, including squamous cell carcinoma of the oesophagus, adenocarcinoma of the distal stomach, as well as a particularly high incidence of adenocarcinoma of the cardia. ${ }^{32}$ This would be consistent with high exposure to a luminal carcinogen exerting its effects throughout this anatomical region and with a predilection for the gastric cardia. Regions of China with a very high incidence of cardia adenocarcinoma also have a high incidence of oesophageal squamous cell carcinoma, again implicating a swallowed carcinogen. ${ }^{26} 33$

Several studies have recently reported that the luminal chemistry of the cardia region is distinct from that of the rest of the stomach or oesophagus. Ingestion of food increases the $\mathrm{pH}$ of most of the stomach due to the buffering effect of the protein but the cardia region remains acidic and this acid pocket facilitates chemical reactions occurring at low $\mathrm{pH}^{34}$ The potential for generation of $\mathrm{N}$-nitroso compounds from dietary nitrate in the acid secreting stomach is also maximal at the cardia region. ${ }^{35}$ Following its absorption, 25\% of circulating nitrate is taken up by salivary glands and secreted into the mouth where it is reduced to nitrite by buccal bacteria. ${ }^{36}{ }^{37}$ This salivary nitrite derived from enterosalivary recirculation of nitrate is the main source of nitrite entering the human stomach. On encountering the acidic $\mathrm{pH}$ of the stomach, nitrite is rapidly converted to nitrous acid and nitrosating species which can react with nitrosatable compounds to form potentially carcinogenic $N$-nitroso compounds. ${ }^{38}$ Acidification of salivary nitrite also generates very high concentrations of nitric oxide which again are maximal in the cardia regions. ${ }^{39}{ }^{40}$ High concentrations of nitric oxide are also thought to be mutagenic. ${ }^{41-46}$ Being a non-solid substance, saliva will follow the lesser curve on entering the stomach. ${ }^{31}$ The Ardabil region is at the foot of a volcano, called Sabalan, and soil nitrate content is being investigated.

The incidence of cardia cancer in the Ardabil region of NW Iran is the highest recorded anywhere in the world and this provides a unique opportunity to investigate its aetiology. Our observation that the tumour usually originates from the right side of the cardia provides an intriguing clue. Elucidating the aetiology of cardia cancer is of great importance due to its rising incidence throughout the world.

\section{Authors' affiliations}

M H Derakhshan, A R Sadjadi, R Malekzadeh, Digestive Disease

Research Centre, Shariati Hospital, Tehran University of Medical Sciences, Tehran, Iran 
A Yazdanbod, B Shokoohi, Department of Medicine and Pathology, Ardabil University of Medical Sciences, Ardabil, Iran

K E L McColl, Section of Medicine, Western Infirmary, Glasgow, UK

\section{REFERENCES}

Parkin DM, Pisano P, Ferlay J. Estimation of the worldwide incidence of 29 major cancers in 1990. Int J Cancer 1999;80:827-41.

2 Blot W, Devesa SS, Kneller RW, et al. Rising incidence of adenocarcinoma of the esophagus and gastric cardia. JAMA 1991;265:1287-9.

3 Powell J, McConkey CC. Increasing incidence of adenocarcinoma of the gastric cardia and adjacent sites. Br J Cancer 1990;62:440-3

4 Botterweck AAM, Schouten $\amalg$, Volovics A, et al. Trends in incidence of adenocarcinoma of the oesophagus and gastric cardia in ten European countries. Int J Epidemiol 2000;29:645-54.

5 Kelley JR, Duggan JM. Gastric cancer epidemiology and risk factors. J Clin Epidemiol 2003;56:1-9.

6 Kodera $Y$, Yamamura Y, Shimizu Y, et al. Adenocarcinoma of the gastroesophageal junction in Japan: relevance of Siewert's classification applied to 177 cases resected at a single institution. J Am Coll Surg 1999;189(6):594-601

7 Uemura N, Okamoto S, Yamamoto S, et al. Helicobacter pylori infection and the development of gastric cancer. N Engl J Med 2001;345:784-9.

8 Hansen S, Vollset SE, Melby K, et al. Gastric mucosal atrophy is a strong predictor of non-cardia gastric cancer but not of cardia cancer. Gastroenterology 1998; 114:G2491

9 Fischermann K, Bech I, Andersen B. Diagnostic value of the augmented histamine test in cancer of the upper part of the stomach. Scand J Gastroenterol 1969:4:517-19.

10 MacDonald WC. Clinical and pathologic features of adenocarcinoma of the gastric cardia. Cancer 1972;29:724-32.

11 Lagergren J, Bergstrom R, Lindgren A, et al. Symptomatic gastroesophageal reflux as a risk factor for esophageal adenocarcinoma. N Engl J Med 1999:340:825-31.

12 Naghavi M. Death in eighteen provinces of Iran. Annual report of Iran Ministry of Health and Medical Education, 2001:127

13 Sadjadi AR, Malekzadeh R, Derakhshan MH, et al. Cancer occurrence in Ardabil: Results of a population-based Cancer Registry from Iran. Int J Cancer 2003;107:113-18.

14 Haghighi P, Nasr K. Gastrointestinal cancer in Iran. J Chron Dis $1971 ; 24: 625-33$

15 Azizi R, Shafiey S. Location of stomach tumours; retrospective study comparing the gastric tumor sub site occurring between 1970-74 and 199094 in Firoozgar General Hospital Tehran. Sci J Irn Med Counsel 1996; 14:144-7.

16 Yazdanbod A, Arshi S, Derakhshan MH, et al. Gastric cardia cancer; the most common type of upper gastrointestinal cancer in Ardabil, Iran. An endoscopy clinic experience. Arch Irn Med 2001;4:1-4.

17 Hamilton SR, Aaltonen LA. WHO classification of tumors, Pathology and genetics of tumors of the digestive system: Tumors of the oesophagogastric junction. Lyon: IARC Press, 2000.

18 dos Santos Silva I. Cancer epidemiology: principles and methods. Lyon: IARC Press, 1999.

19 Breslow NE, Day NE. Statistical Methods in Cancer Research, vol II. The Design and Analysis of Cohort Studies (IARC Scientific Publications No 82) Lyon: International Agency for Research on Cancer, 1987:72-6.

20 Cancer Incidence in Five Continents, vol VIII. In: Parkin DM, Whelan SL, Ferlay J, et al, eds. Lyon: IARC Scientific Publications, 2002:No. 155

21 Powell J, McConkey CC. Increasing incidence of adenocarcinoma of the gastric cardia and adjacent sites. Br J Cancer 1990;62:440-3

22 Hansen S, Wiig JN, Giercksky KE, et al. Esophageal and gastric carcinoma in Norway 1958-1992: incidence time trend variability according to morphological subtypes and organ subtypes. Int J Cancer 1997;71:340-4.
23 Botterweck AAM, Schouten $\sqcup$, Volovics A, et al. Trends in incidence of adenocarcinoma of the oesophagus and gastric cardia in ten European countries. Int J Epidemiol 2000;29:645-54.

24 Lee JY, Kim HY, Kim KH, et al. No changing trends in incidence of gastric cardia cancer in Korea. J Korean Med Sci 2003;18:53-7.

25 Cancer Information. Tables of cancer data of Scottish Cancer Registry. www.show.scot.nhs.uk accessed 3 August, 2003

26 Limburg P, You-Lin Qiao, Mark SD, et al. Helicobacter pylori seropositivity and subsite-specific gastric cancer risks in Linxian, China. J Natl Cancer Inst 2001;93:226-33.

27 Helicobacter and Cancer Collaborative Group. Gastric cancer and Helicobacter pylori: a combined analysis of 12 case control studies nested within prospective cohorts. Gut 2001;49:347-53.

28 Hansen S, Melby KK, Aase S, et al. Helicobacter pylori infection and risk of cardia cancer and non-cardia gastric cancer. Scand J Gastroenterol 1999;334:353-60.

29 Malekzadeh R, Sotoudeh M, Derakhshan MH, et al. Prevalence of gastric precancerous lesions in Ardabil, a high incidence province for gastric adenocarcinoma in the north west of Iran. J Clin Pathol 2004;57:37-42.

30 Jeffferson $\mathbf{G}$. The human stomach and the canalis gastricus (Lewis). J Anat 1915;49:165-81.

31 Cassaro M, Rugge M, Gutierrez O, et al. Topographic patterns of intestinal metaplasia and gastric cancer. Am J Gastroenterol 2000;95:1431-8.

32 Saidi F, Malekzadeh M, Sotoudeh M, et al. Endoscopic esophageal cancer survey in the western part of the Caspian Littoral. Dis Esophagus 2002;15:214-8.

33 Wang L-D, Zheng S, Zheng Z-Y, et al. Primary adenocarcinomas of lower esophagus, esophagogastric junction and gastric cardia: in special reference to China. World J Gastroenterol 2003;9:1156-64.

34 Fletcher J, Wirz A, Young J, et al. Unbuffered highly acidic gastric juice exists at the gastresophageal junction after a meal. Gastroenterology $2001 ; 121: 775-83$

35 Suzuki H, lijima K, Moriya A, et al. Conditions for acid catalysed luminal nitrosation are maximal at the gastric cardia. Gut 2003;52:1095-101.

36 Gangolli S D, van den Brandt P, Feron VJ, et al. Nitrate, nitrite and N-nitroso compounds. Eur J Pharmacol Environm Toxicol Pharmacol 1994;292:1-38.

37 Van Maanen JM, van Geel AA, Kleinjans JC. Modulation of nitrate-nitrite conversion in the oral cavity. Cancer Detect Prev 1996;20:590-6.

38 Leach S. Mechanisms of endogenous N-nitrosation. In: Hill J, ed. Nitrosoamines: toxicology and microbiology. London: Ellis Holwood, 1988:69-87.

39 Lundberg JON, Weitzberg E, Lundberg JM, et al. Intragastric nitric oxide production in humans: measurement in expelled air. Gut 1994;35:1543-6.

40 lijima K, Henry E, Moriya A, et al. Dietary nitrate generates potentially mutagenic concentrations of nitric oxide at the gastroesophaeal junction. Gastroenterology 2002;122:1248-57.

41 Felley-Bosco E. Role of nitric oxide in genotoxicity: Implication for carcinogenesis. Cancer Metastasis Rev 1998;17:25-37.

42 Moochhala S, Rajanakova A. Role of nitric oxide in cancer biology. Free Radic Res 1999;31:671-9.

43 Jaiswal M, LaRusso N F, Shapiro R A, et al. Nitric oxide-mediated inhibition of DNA repair potentiates oxidative DNA damage in cholangiocytes. Gastroenterology 2001;120:190-9.

44 Laval F, Wink DA, Laval J. A discussion of mechanisms of NO genotoxicity: implication of inhibition of DNA repair proteins. Rev Physiol Biochem Pharmacol 1997;131:175-91.

45 Liu L, Xu-Welliver M, Kanugula S, et al. Inactivation and degradation of $\mathrm{O}^{6}$. alkylguanine-DNA alkyltransferase after reaction with nitric oxide. Cancer Res 2002;62:3037-43.

46 Li C-Q, Trudel U, Wogan GN. Nitric oxide-induced genotoxicity, mitochondrial damage, and apoptosis in human lymphoblastoid cells expressing wild-type and mutant p53. Proc Natl Acad Sci U S A 2002;99:10364-19.

\section{EDITOR'S QUIZ: GI SNAPSHOT}

\section{Answer}

From question on page 1261

The scan demonstrates an intragastric mass with a whorled configuration containing multiple small pockets of air. Free air is also seen in the peritoneal cavity, suggesting gastric perforation, most probably as a result of pressure necrosis from trichobezoar causing ulceration and subsequent perforation.

The patient had a subsequent gastrotomy where a huge trichobezoar was removed from the stomach. It later transpired that the patient had eaten her hair as an adolescent and that she had recently been discharged from a local dermatology clinic following treatment for alopecia.

Attempting to establish a clinical diagnosis of trichobezoar is extremely challenging as symptoms may mimic other pathologies. Eliciting a history of trichophagia, the presence of alopecia, and a high index of suspicion may all aid the clinician, but more often than not, the diagnosis, as in this case, is made only after radiological investigation.

doi: $10.1136 /$ gut.2003.033589 